\title{
Effects of Travel Routes on Vehicular Emissions in Urban Driving
}

\author{
O.N Aduagba ${ }^{1}$ J. D. Amine ${ }^{2}$ and M.I. Oseni ${ }^{2}$ \\ ${ }^{I}$ Raw Materials Research and Development Council, Abuja, Nigeria \\ ${ }^{2}$ University of Agriculture, Department of Mechanical Engineering, Markudi, Nigeria
}

\begin{abstract}
This study measured the concentration of pollutants in a passenger car Golf 3, Volkswagen model, popularly used as Taxi in Nigeria was done on three different travel routes of state routes in the Federal Capital Territory, Abuja, in the bid to compare the emission level of regulated and non-regulated gasses of Carbon monoxide $(\mathrm{CO})$, Carbon dioxide $\left(\mathrm{CO}_{2}\right)$, Nitrogen oxide (NO), and Non-Methane Hydro Carbon (NMHC) propane using SV -5Q Automobile Exhaust Gas Analyzer connected to the exhaust port with measurement conducted at intervals over traveled distance. The Route C (Berger-Areal) gave the lowest average emissions value of 0.45\%, 87.69\%, 320.72ppm and 590.86 ppm for CO, $\mathrm{CO}_{2}, \mathrm{HC}$ and $\mathrm{NO}$, Route B (Nyanya- AYA) gave the highest value of $0.53 \% \mathrm{CO}, 8.99 \% \mathrm{CO}_{2}, 374.06 \mathrm{ppm} \mathrm{HC}$ and $691.52 \mathrm{ppm} \mathrm{NO}$. In percentage analysis the average emission value for $\mathrm{CO}$ in route B was $6 \%$ higher while Route A (Jikwoyi-Kurudu) $3 \%$ higher than the value in Route $\mathrm{C}$. Also the $\mathrm{CO}_{2}$ average emission was $6 \%$ higher in Route $\mathrm{B}$ than Route $\mathrm{C}$ similar to observation in $\mathrm{CO}$ but in Route $\mathrm{A}$ the $\mathrm{CO}_{2}$ value was $5 \%$ lower than Route $C$. The road grade should be taken into account for localized emissions estimation
\end{abstract}

Keyword: Altitude, Average Speed, Emissions, Travel Routes,

\section{Introduction}

Estimating emissions has been considered a significant problem due to an increasing world's vehicle fleet, population growth, and urbanisation making automobiles the dominator of passengers' transport. Only a few countries, like the U.S. have developed reasonably accurate emissions projection tools, and these are designed only for their respective regions. The focus of this research is to study the emissions in three different travel routes in the City of Abuja, Nigeria. The survey of many literatures shows gaps in study of emissions and identification of influencing variables in Abuja city.

Despite improvement in engine design in recent years, there is still high level of exhaust emissions from cars, road transport activities still contribute significantly to environmental problems at different geographical levels. Issues of concern include local exposure to air pollutants in areas with heavy traffic, photochemical smog formation, national emission levels of primary air pollutants and global warming. With various studies carried out on fuel related emissions and operational characteristics on a number of vehicles, motor vehicle emissions are inadequately quantified. The accepted standard for vehicular emission is the European standard adopted by most countries globally, based on certain emission values. Nigeria does not have an emission value, the ultimate use of this study would be to provide data for transport system planners and environmental analyst create a realistic city fuel-economy and emission tests. The continuously tightening of emission standards for vehicles globally as become a policy in lowering average vehicle emissions over time, the study will equally allow us to design recommendations or guidelines for the emission factor measurement of Nigeria' vehicles. The depletion of the ozone layer due to unabated emissions also plays a critical role in screening harmful ultraviolet radiation which allows the harmful radiation to reach the earth surface. This in turn as lead to a greater incidence and affect physiological and developmental processes in plants; as many governments all over the world is making decisions to develop and introduce a range of measures to reduce the growing harmful health and environmental impacts of vehicle emissions.

According to Ibrahim [1] from the study carried out in three major towns in Benue State, Nigeria using UV/vis spectrophotometer Cecil model1000 that $\mathrm{CO}_{2}-\mathrm{CO}$ is the most dominant pollutant in air. The study also showed presence of other pollutants in magnitude of $\mathrm{SO}_{2}$ greater than $\mathrm{NO}_{2}-\mathrm{NOx}$ greater than $\mathrm{HC}$ greater than $\mathrm{H}_{2} \mathrm{~S}$ in Markudi, Gboko and Otukpo respectively. The varying values resulted from the valley nature of markudi location which required acceleration as the vehicle drives out of town, while Gboko town was in a higher altitude than Otukpo. The study also showed an increasing number of motor vehicles and motorcycles in these locations which were the major contribution of air pollution. Frey HC [2] conclude that positive road grades were associated with an approximately $20 \%$ increase in localized emissions rates, while negative road grades were associated with a similar relative decrease. This study has help in further understanding the relationship between emissions and fuel consumption in roads with vary grade, altitude and average speed of travel. 
a) SV-5Q Automobile Exhaust Gas Analyzer

\section{Materials}

b) SV-1 Engine Tachometer

c) Volkswagen (Golf GTi Model 1996)

d) Black and Decker 400 (watt) Inverter

e) HP Laptop with SV-5Q Gas Analyzer PC Contactor Interface Software System

f) Routes

\section{Method}

Vehicular emissions of the investigative car were measured using a SV-5 exhaust gas analyzer along the routes of study namely: Jikwoyi to Kurudu; Yanyan to AYA; and Berger to Area1 in Abuja FCT. The gases investigated were carbon monoxide, Carbon dioxide, Nitrogen oxide, Non-Methane Hydrocarbon (NMHC) i. e propane and Oxygen.

The Gas analyzer is set for the emission tests by connecting one side of sampling tube to the end of sampling while the other side is connected to the exit of fronted filter. Connecting one side of short catheter with the front of fronted filter, while the other side is connected to sample gas vent of the analyzer. Every point is then checked to make sure they are firmly connected and no leakages. The 1-meter-long soft pipe is then connected to the oxygen vent, this is done after fronted filter, oil-moisture separator and secondary filter have been put in clean filter paper and filter heart separately.

Followed is separately connecting the power line, engine temperature measurement and speed tachometer, temperature signal socket and speed signal socket. The analyzer is then powered and immediately goes into preheating for duration of 10 minutes for the analyzer to warm up. A leak check is then followed after preheating, the analyzer will enter sub menu "leaking check" automatically to check if gas lines system leaks. After the analyzer must have been through with the leak check it then proceeds into Auto Zeroing Proceeding the Auto zeroing is the $\mathrm{HC}$ remainder inspection, the analyzer inspects $\mathrm{HC}$ remainder automatically.

In order to meet requirements of vehicle stroke investigation, the engine stroke and cylinder amount are selected, that is 4 stroke engine and 4 cylinders. The analyzer is now ready for general measurement showing real time measurement. It is suitable to observe real value of vehicle exhaust gas in either the idle mode or simple driving mode condition. The OK" button is pressed to start the analyzer.

The results on the analyzer were recorded at $1 \mathrm{~km}$ intervals over the travelled distance and the average reading calculated. The test also involved the record of the ambient temperatures, atmospheric pressures, average speeds of travels and fuel consumptions at $\mathrm{L} / 100 \mathrm{~km}$ in the duration of the tests.

The experimental tests were conducted between the hours of 8 am and 4pm when traffic is high for duration of fourteen days. The tests were conducted without the car air-condition and sound systems and the researcher as the only passenger (weight $67 \mathrm{Kg}$ ) making at total gross weight of the vehicle equal $1131 \mathrm{Kg}$. The driving pattern represents the actual urban driving style that involves the vehicle accelerating and decelerating at intervals and all the driving gears engaged as the vehicle speed demands. With the SV-5 Gas analyzer, the preinstalled software package enables the device to be connected to a personal computer (PC) and the data are recorded on real-time basis.

\section{Results}

Table 1: Summary of Mean Values of Emissions on Route A (Jikwoyi-Kurudu)

\begin{tabular}{|c|c|c|c|c|c|c|c|c|c|}
\hline Test & $\begin{array}{l}\text { Travel } \\
\text { Time } \\
\text { Duration } \\
\text { (min) }\end{array}$ & $\begin{array}{l}\text { Average } \\
\text { Speed } \\
(\mathbf{K m} / \mathbf{h r})\end{array}$ & $\begin{array}{l}\text { Fuel Cons. } \\
\text { (L/100km) }\end{array}$ & $\begin{array}{l}\mathrm{CO} \\
(\%)\end{array}$ & $\begin{array}{l}\mathrm{CO}_{2} \\
(\%)\end{array}$ & $\begin{array}{l}\text { HC } \\
(\mathbf{p p m})\end{array}$ & $\begin{array}{l}\mathrm{O}_{2} \\
(\%)\end{array}$ & $\begin{array}{l}\text { NO } \\
(\mathbf{p p m})\end{array}$ & $\begin{array}{l}\square \\
\text { (air/fuel } \\
\text { equivalen } \\
\text { ce ratio) } \\
\end{array}$ \\
\hline Test1 & 1.34 & 46.29 & 7.74 & 0.33 & 9.98 & 190.86 & 0.69 & 915.57 & 1.02 \\
\hline Test 2 & 2.36 & 50.16 & 13.625 & 0.32 & 9.42 & 196.86 & 1.08 & 1620.43 & 1.05 \\
\hline Test 3 & 1.58 & 46.29 & 14.61 & 1.25 & 8.30 & 386.29 & 2.73 & 290.10 & 1.10 \\
\hline Test 4 & 1.54 & 42.57 & 16.83 & 0.76 & 8.15 & 390.86 & 2.07 & 870.30 & 1.07 \\
\hline Test 5 & 1.58 & 38.71 & 10.94 & 0.51 & 8.64 & 389.71 & 2.61 & 757.00 & 1.14 \\
\hline Test 6 & 1.33 & 46.86 & 12.33 & 0.27 & 8.58 & 147.71 & 1.40 & 331.00 & 1.29 \\
\hline Test 7 & 2.06 & 33.71 & 15.81 & 0.36 & 7.85 & 521.71 & 3.20 & 539.57 & 1.07 \\
\hline Test8 & 1.58 & 39.57 & 11.99 & 0.31 & 7.69 & 278.14 & 1.92 & 199.43 & 1.15 \\
\hline Test9 & 1.58 & 39.00 & 9.10 & 0.31 & 7.17 & 517.43 & 2.77 & 397.86 & 1.18 \\
\hline Test10 & 1.58 & 39.43 & 8.90 & 0.32 & 7.84 & 298.00 & 1.47 & 322.29 & 1.09 \\
\hline
\end{tabular}


Effects Of Travel Routes On Vehicular Emissions In Urban Driving

\begin{tabular}{lllllllllll}
\hline Test11 & 1.76 & 41.14 & 9.10 & 0.78 & 7.37 & 468.71 & 2.12 & 701.71 & 1.11 \\
& & & & & & & & & & \\
Test12 & 1.58 & 39.00 & 9.50 & 0.35 & 7.65 & 316.29 & 2.04 & 196.86 & 1.13 \\
Test13 & 1.42 & 42.86 & 8.01 & 0.60 & 8.18 & 405.43 & 1.32 & 546.71 & 1.05 \\
Test14 & 1.57 & 40.43 & 9.56 & 0.35 & 8.03 & 265.43 & 1.29 & 1088.57 & 1.07 \\
Mean & 1.63 & 41.86 & 11.29 & 0.49 & 8.20 & 340.95 & 1.91 & 626.9 & 1.11 \\
\hline
\end{tabular}

Table 2: Summary of Mean Values of Emissions on Route B (Yanyan- AYA Road)

\begin{tabular}{|c|c|c|c|c|c|c|c|c|c|}
\hline Test & $\begin{array}{l}\text { Travel } \\
\text { Time } \\
\text { (min) }\end{array}$ & $\begin{array}{l}\text { Average } \\
\text { Speed } \\
(\mathbf{K m} / \mathbf{h r})\end{array}$ & $\begin{array}{l}\text { Fuel Cons. } \\
\text { (L/100km) }\end{array}$ & $\begin{array}{l}\text { CO } \\
(\%)\end{array}$ & $\begin{array}{r}\mathrm{CO}_{2} \\
(\%)\end{array}$ & $\begin{array}{l}\text { HC } \\
(\mathbf{p p m})\end{array}$ & $\begin{array}{l}\mathbf{O}_{2} \\
(\%)\end{array}$ & $\begin{array}{l}\text { NO } \\
(\mathrm{ppm})\end{array}$ & $\begin{array}{l}\square \\
\text { (air/fuel } \\
\text { equiv. } \\
\text { ratio) }\end{array}$ \\
\hline Test 1 & 1.21 & 41.66 & 8.51 & 0.36 & 10.98 & 209.95 & 0.62 & 1007.13 & 1.12 \\
\hline Test 2 & 3.07 & 37.12 & 14.44 & 0.34 & 9.99 & 208.67 & 0.97 & 1717.66 & 1.11 \\
\hline Test 3 & 1.66 & 27.77 & 14.90 & 1.28 & 8.55 & 397.88 & 2.45 & 298.84 & 1.13 \\
\hline Test 4 & 1.62 & 40.44 & 18.51 & 0.84 & 9.54 & 457.31 & 1.86 & 1018.24 & 1.25 \\
\hline Test 5 & 1.58 & 40.26 & 10.94 & 0.61 & 10.45 & 471.55 & 2.35 & 915.97 & 1.38 \\
\hline Test 6 & 1.49 & 42.17 & 13.07 & 0.29 & 9.18 & 158.05 & 1.26 & 354.17 & 1.38 \\
\hline Test 7 & 2.35 & 28.99 & 14.23 & 0.32 & 7.76 & 515.97 & 2.88 & 533.63 & 1.06 \\
\hline Test 8 & 1.83 & 33.24 & 11.99 & 0.34 & 8.69 & 314.30 & 1.73 & 225.36 & 1.30 \\
\hline Test 9 & 1.90 & 42.90 & 9.65 & 0.33 & 7.59 & 547.96 & 2.49 & 421.33 & 1.25 \\
\hline Test 10 & 1.67 & 33.52 & 9.26 & 0.33 & 8.31 & 315.88 & 1.32 & 341.63 & 1.16 \\
\hline Test 11 & 1.57 & 41.14 & 10.92 & 0.94 & 9.07 & 576.51 & 1.91 & 863.10 & 1.37 \\
\hline Test 12 & 1.90 & 36.66 & 9.41 & 0.35 & 8.42 & 347.92 & 1.83 & 216.55 & 1.24 \\
\hline Test 13 & 1.26 & 47.15 & 8.34 & 0.62 & 8.53 & 422.86 & 1.19 & 570.22 & 1.10 \\
\hline Test 14 & 1.54 & 35.17 & 12.43 & 0.44 & 8.83 & 291.97 & 1.16 & 1197.43 & 1.18 \\
\hline Mean & 1.76 & 37.73 & 11.90 & 0.53 & 8.99 & 374.06 & 1.72 & 691.52 & 1.22 \\
\hline
\end{tabular}

Table 3: Summary of Mean Values of Emissions on Route C (Berger- Area 1 Road

\begin{tabular}{cccccccccc}
\hline Test & $\begin{array}{c}\text { Travel } \\
\text { Time } \\
(\mathbf{m i n})\end{array}$ & $\begin{array}{c}\text { Average } \\
\text { Speed } \\
(\mathbf{K m} / \mathbf{h r})\end{array}$ & $\begin{array}{c}\text { Fuel } \\
\mathbf{C o n s} \\
(\mathbf{L} / \mathbf{1 0 0} \\
\mathbf{k m})\end{array}$ & $\begin{array}{c}\mathbf{C O} \\
\mathbf{( \% )}\end{array}$ & $\begin{array}{c}\mathbf{C O}_{\mathbf{2}} \\
\mathbf{( \% )}\end{array}$ & $\begin{array}{c}\mathbf{H C} \\
(\mathbf{p p m})\end{array}$ & $\begin{array}{c}\mathbf{O}_{\mathbf{2}} \\
(\boldsymbol{\%})\end{array}$ & $\begin{array}{c}\mathbf{N O} \\
(\mathbf{p p m})\end{array}$ & $\begin{array}{c}\square \\
\text { (air/fuel } \\
\text { equiv. } \\
\text { ratio) }\end{array}$ \\
\hline Test 1 & 1.03 & 45.83 & 7.24 & 0.31 & 9.33 & 178.45 & 0.53 & 856.06 & 0.95 \\
Test 2 & 2.76 & 44.54 & 11.99 & 0.28 & 8.29 & 173.20 & 0.81 & 1425.6 & 0.92 \\
& & & & & & & & 5 & \\
Test 3 & 1.36 & 36.11 & 11.92 & 1.02 & 6.84 & 318.30 & 1.96 & 239.08 & 0.91 \\
Test 4 & 1.31 & 44.49 & 15.92 & 0.72 & 8.20 & 393.28 & 1.60 & 875.69 & 1.08 \\
Test 5 & 1.45 & 48.31 & 9.19 & 0.51 & 8.78 & 396.10 & 1.97 & 769.41 & 1.16 \\
Test 6 & 1.27 & 46.39 & 10.85 & 0.24 & 7.62 & 131.18 & 1.04 & 293.96 & 1.15 \\
Test 7 & 2.07 & 37.69 & 12.81 & 0.29 & 6.99 & 464.37 & 2.59 & 480.27 & 0.95 \\
Test 8 & 1.65 & 44.87 & 10.91 & 0.31 & 7.91 & 286.01 & 1.57 & 205.07 & 1.18 \\
Test 9 & 1.73 & 54.91 & 8.39 & 0.29 & 6.61 & 476.72 & 2.17 & 366.56 & 1.09 \\
Test 10 & 1.46 & 40.22 & 7.96 & 0.29 & 7.15 & 271.66 & 1.14 & 293.80 & 0.99 \\
Test 11 & 1.39 & 45.25 & 9.17 & 0.79 & 7.61 & 484.27 & 1.60 & 725.01 & 1.15 \\
Test 12 & 1.42 & 44.73 & 7.81 & 0.29 & 6.98 & 288.77 & 1.52 & 179.73 & 1.03 \\
Test 13 & 1.15 & 57.52 & 7.25 & 0.54 & 7.42 & 367.89 & 1.03 & 496.09 & 0.95 \\
Test 14 & 1.23 & 43.97 & 11.06 & 0.39 & 7.86 & 259.86 & 1.03 & 1065.7 & 1.05 \\
& & & & & & & & 1 & \\
Mean & 1.52 & 45.34 & 10.18 & 0.45 & 7.69 & 320.72 & 1.47 & 590.86 & 1.04 \\
\hline
\end{tabular}




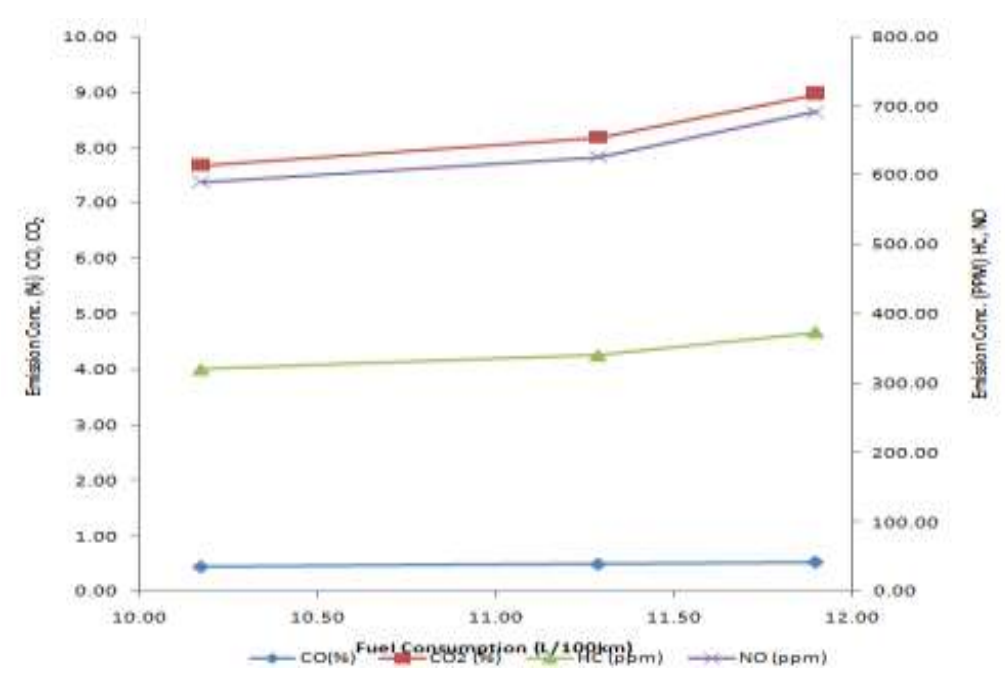

Figure.1 : Plot of fuel consumption with exhaust emissions at on-road

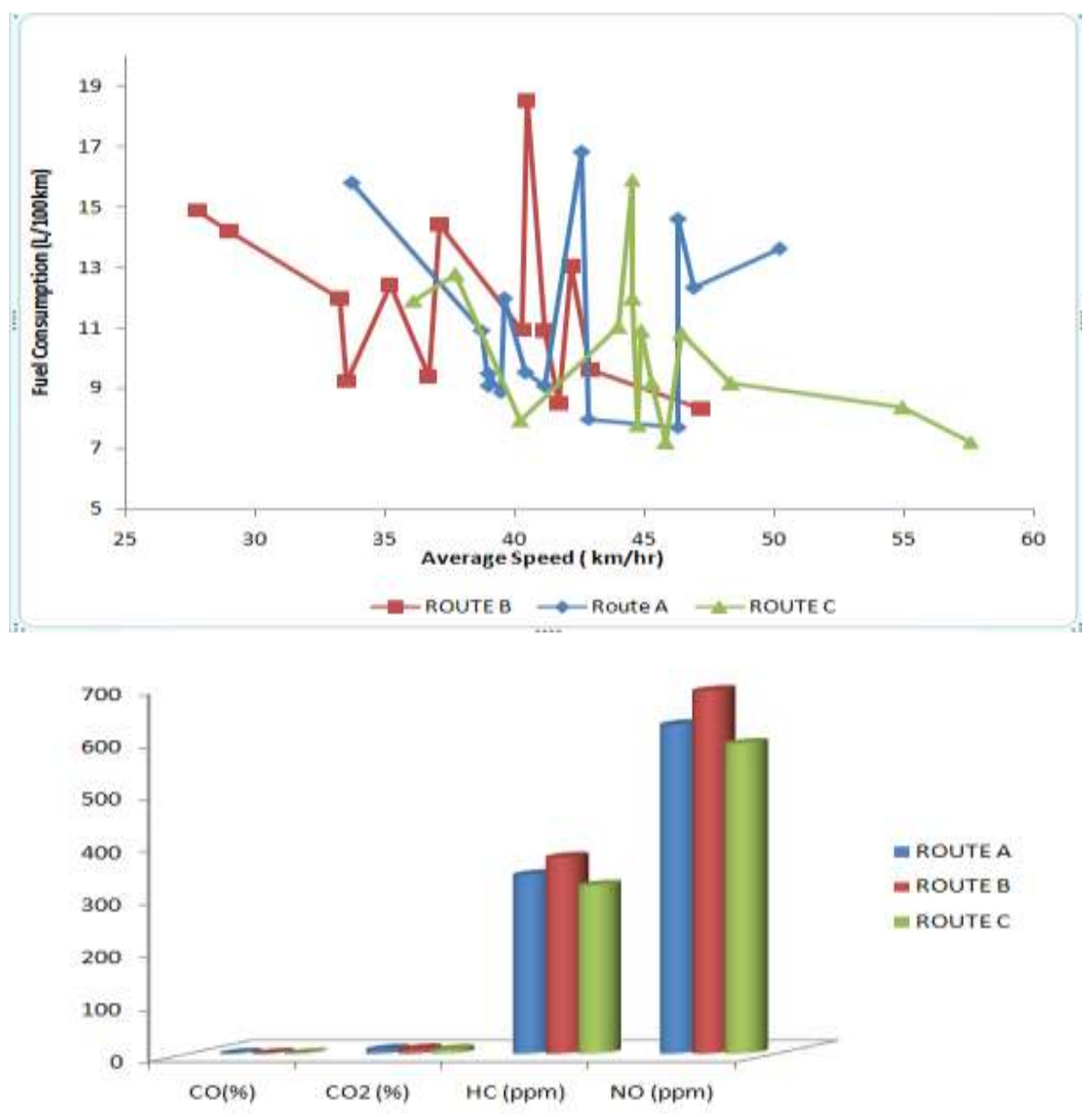

Figure 3: Plot of mean emissions values on-road test for Route A, B, C

\section{Discussions}

From fig. 1 it can be seen that emission concentration increases as the fuel consumption move from 10.18 to $11.901 / 100 \mathrm{~km}$ and the recorded $\mathrm{CO}$ values ranged between $0.45 \%$ to $0.53 \%$ maximum mean value, $\mathrm{CO}_{2}$ had values of $7.69 \%$ to $8.99 \%$. The results of the $\mathrm{HC}$ show a minimum value of $320.72 \mathrm{ppm}$ and maximum $340.95 \mathrm{ppm}$. In the observed results the value of $\mathrm{NO}$ was recorded as $590.86 \mathrm{ppm}$ and $691.52 \mathrm{ppm}$ maximum value from the mean results of the routes tests conducted. These observations are expected as increase in fuel consumption will increase emissions from the theoretical point of view of combustion process 
that the air /fuel ratio decreased as more fuel is consumed for instance, the carbon monoxide concentrations emitted will increase as incomplete combustion is triggered at lower air to fuel ratio. This was also supported and demonstrated by Heywood [3].Andrew [4] also inferred that even under the same acceleration emissions has a closer relationship with fuel consumption. Similarly, Andrew [4] and Chan [5], which both found that a number of variables such as fuel consumption, speed and acceleration affect emission.

Fig.2 shows the fuel consumption and average speed of travel of the vehicle under investigation at the different routes of study. The summary of the results from Route A show an average speed of $42.57 \mathrm{~km} / \mathrm{hr}$ and $46.29 \mathrm{~km} / \mathrm{hr}$ corresponding to the fuel consumption maximum value of $16.83 \mathrm{l} / 100 \mathrm{~km}$ and to $7.741 / 100 \mathrm{~km}$ minimum value respectively. Route B similarly, show decrease in fuel consumption from $18.51 \mathrm{l} / 100 \mathrm{~km}$ maximum to $8.341 / 100 \mathrm{~km}$ minimum at average speed of $40.14 \mathrm{~km} / \mathrm{hr}$ and $47.15 \mathrm{~km} / \mathrm{hr}$ respectively. Decrease in fuel consumption was also noted in Route $C$ that recorded average speed range of $44.49 \mathrm{~km} / \mathrm{hr}$ to $45.93 \mathrm{~km} / \mathrm{hr}$ with the fuel consumption dropping from $15.921 / 100 \mathrm{~km}$ to $7.241 / 100 \mathrm{~km}$. The fuel consumptions values noticed in Route C significant decrease as the vehicle speed approached $60 \mathrm{~km} / \mathrm{hr}$. The general fact that fuel consumption is influenced by any slight change in vehicle speed and get more complex was observed as reported by Eggleston [6]. Nairn and Partners [7] also find out that to reduce fuel consumption drive speed must approach $60 \mathrm{~km} / \mathrm{hr}$. Andrew [4] also inferred from his study that low speeds conditions with frequent accelerations and decelerations were main factors aggravated and caused high emissions as more fuel is burned. And speed from $20 \mathrm{~km} / \mathrm{hr}$ to $60 \mathrm{~km} / \mathrm{hr}$ due to air resistance will increase significantly fuel consumption, as the speed of the vehicle decrease the air velocity around the vehicle will increase causing increase in the aerodynamic drag causing the fuel consumption to increase.

Fig. 3 compares the emission values at selected driving routes A, B, C having vary road altitude, traffic and grade (slope) as demonstrated. The Route $\mathrm{C}$ gave the lowest average emissions value of $0.45 \%, 87.69 \%$, $320.72 \mathrm{ppm}$ and $590.86 \mathrm{ppm}$ for $\mathrm{CO}, \mathrm{CO}_{2}, \mathrm{HC}$ and $\mathrm{NO}$ respectively with respect to average emissions generated over travelled distance, while Route B gave the highest value of $0.53 \% \mathrm{CO}, 8.99 \% \mathrm{CO} 2,374.06 \mathrm{ppm} \mathrm{HC}$ and $691.52 \mathrm{ppm}$ NO . In percentage analysis the average emission value for $\mathrm{CO}$ in route $\mathrm{B}$ was $6 \%$ higher and Route A 3\% higher than the value in Route $\mathrm{C}$. Also the $\mathrm{CO}_{2}$ average emission was $6 \%$ higher in Route $\mathrm{B}$ than Route $\mathrm{C}$ similar to observation in $\mathrm{CO}$ but in Route $\mathrm{A}$ the $\mathrm{CO}_{2}$ value was $5 \%$ lower than Route $\mathrm{C}$ this can be attributed to ambient conditions of the vehicle operating environment as reported by Vijayan [8]. The measured average emission value for $\mathrm{HC}$ was $0.7 \%$ and $5 \%$ higher in Route A and Route B respectively than in Route C, while for NO Route B was 5\% and Route A $0.5 \%$ higher. Many factors have been shown to influence vehicle emissions this results indicates that the amount of emissions also depend on the travel route type and traffic. The Route B is more congested than others, and the differences in altitude between points of travel which was $1.5 \mathrm{~m}, 69.93 \mathrm{~m}$ and $0.36 \mathrm{~m}$ for Routes A, Route B and Route C respectively explaining reason for vehicle emission variations rather than speed and acceleration, and aerodynamic drag alone as reported by Jimenez, [9].

\section{Conclusion}

Less fuel is consumed and lower level emissions are experience at as vehicle speeds increase and approaches $60 \mathrm{~km} / \mathrm{hr}$. Emission values differ in the range of $0.5-5 \%$ on travelled routes with different altitude, traffic and road grade. The road grade and altitude should be taken into account for localized.

\section{References}

[1] Ibrahim J.S., Kucha E.I., and Ukwenya J. (2009) Evaluation of the Level of Urban Pollution caused by Automobile Exhaust Gases in Three major Towns of Benue State. Multidisciplinary Journal of Research Development, Published by National Association of Research Development Vol. 13 No, pp40-44

[2] Frey HC, Zhang K, Rouphail NM. (2008) Fuel use and emissions comparisons for alternative routes, time of day, road grade, and vehicles based on in-use measurements. Environmental Science and Technology pp 10

[3] Heywood B. (1988). Internal combustion Engine Fundamentals (International Edition). McGraw- Hill, New York, pp38

[4] Andrew J. K., Robert A. H. and Gary R. K.(2003). Effects of Vehicle Speed and Engine Load on Motor Vehicle Emissions .Environmental. Science and Technology. pp 3739

[5] Chan T.L., Ning Z., Leung C.W., Cheung C.S., Hung W.T. and Dong G. (2004) On- road remote sensing of petrol vehicle emissions measurement and emission factors estimation in Hong Kong. Atmospheric 140 Environment 38, pp205

[6] Eggleston S., Gaudioso D., Gorissen N., Joumard R., Rijkeboer R. C., Samaras Z., and Zierock K. H., (1993) CORINAIR Working Group on Emission Factors for Calculating 1990 Emissions from Road Traffic. Volume 1: Methodology and emission factors. Final Report. Document of the European Commission ISBN 92-826-5571-X. pp 120

[7] Nairn and Partners. (1994). Leonie Segal Economic Consultants and Watson Victorian transport externalities study 3. Strategies for reducing emissions of greenhouse gases and ozone precursors from land-based transport. Report prepared for EPA, Melbourne. pp24

[8] Vijayan A. (2007) Characterization of Vehicular Exhaust Emissions and Indoor Air Quality of Public Transport Buses Operating on Alternative Diesel Fuels. PhD Dissertation

[9] Jimenez T. (1999). Case studies of particulate emissions from in-use of nitrous oxide emissions from motor vehicles. pp154 